University of New Mexico

UNM Digital Repository

$1-1-1975$

\title{
The evolution of alarm calls: Altruism or manipulation?
}

Eric Charnov

John R. Krebs

Follow this and additional works at: https://digitalrepository.unm.edu/biol_fsp

Part of the Biology Commons

\section{Recommended Citation}

American Naturalist 109:107-112

This Other is brought to you for free and open access by the Academic Department Resources at UNM Digital Repository. It has been accepted for inclusion in Biology Faculty \& Staff Publications by an authorized administrator of UNM Digital Repository. For more information, please contact disc@unm.edu. 
The Evolution of Alarm Calls: Altruism or Manipulation?

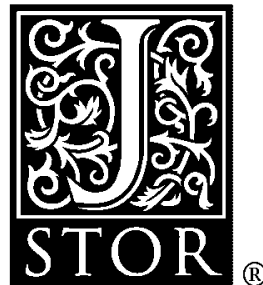

\author{
Eric L. Charnov; John R. Krebs
}

The American Naturalist, Vol. 109, No. 965 (Jan. - Feb., 1975), 107-112.

Stable URL:

http://links.jstor.org/sici?sici=0003-0147\%28197501\%2F02\%29109\%3A965\%3C107\%3ATEOACA\%3E2.0.CO\%3B2-R

The American Naturalist is currently published by The University of Chicago Press.

Your use of the JSTOR archive indicates your acceptance of JSTOR's Terms and Conditions of Use, available at http://www.jstor.org/about/terms.html. JSTOR's Terms and Conditions of Use provides, in part, that unless you have obtained prior permission, you may not download an entire issue of a journal or multiple copies of articles, and you may use content in the JSTOR archive only for your personal, non-commercial use.

Please contact the publisher regarding any further use of this work. Publisher contact information may be obtained at http://www.jstor.org/journals/ucpress.html.

Each copy of any part of a JSTOR transmission must contain the same copyright notice that appears on the screen or printed page of such transmission.

JSTOR is an independent not-for-profit organization dedicated to creating and preserving a digital archive of scholarly journals. For more information regarding JSTOR, please contact support@jstor.org. 
So we may conclude that certain insects cross hard-surface roads by the shortest possible route in a tropistic response to the symmetry of radiant energy coming from up and down the road. The response is made by both flying and crawling insects, but it is not made by all flying insects (e.g., dragonflies). Such behavior has survival value for crawling insects, for it causes them to spend the least possible time on hot and heavily traveled highways. Similarly, this response leads insects to cross bare spots of the earth in the shortest possible time.

LITERATURE CITED

Cloudsley-Thompson, J. L. 1969. The zoology of tropical Africa. Norton, New York. $355 \mathrm{pp}$.

Hirsch, J. 1973. Introduction. Pages v-xxvi in Jacques Loeb, Forced movements, tropisms, and animal conduct. Dover, New York. 209 pp. [First published in 1918.]

Northrop, J. H. 1961. Biochemists, biologists, and William of Occam. Annu. Rev. Biochem. $30: 1-10$.

Page, J. K. 1974. Phenomena, comment, and notes. Smithsonian, vol. 4, no. 11.

Gordon GuNTER

\author{
Gulif Coast Research Laboratory \\ OCEan Springs, Mississippi 39564 \\ June 24, 1974
}

\title{
THE EVOLUTION OF ALARM CALLS: ALTRUISM OR MANIPULATION?
}

In many species of passerine birds a member of a flock gives a special alarm call when it sees an aerial predator (Thorpe 1961). The whole flock immediately takes off and heads for cover. The birds freeze if they are already in cover. This phenomenon has been discussed from an evolutionary point of view (Maynard Smith 1965; Trivers 1971; Williams 1970; Emlen 1973), since it apparently is a classic case of altruistic behavior. Altruism means that the act of calling increases the survival chances of nearby conspecifics while placing the caller in greater immediate danger. If the members of the flock are closely related, altruistic calling can evolve through kin selection (Hamilton 1964). However, alarm calls are given not just in the presence of close kin, but also outside the breeding season after migration and dispersal (Trivers 1971). Calling perhaps originated in family groups but how has the habit come to be found in groups that are not of close kin, assuming that the call would be suppressed in nonkin groups if this were advantageous to the caller individuals? Any hypothesis must allow that initially some callers were penalized by selection, since otherwise it is not possible to explain why the calls of several different species are convergent 
(Marler 1955). It is this convergence that has been cited as evidence that calling is (or was) altruistic.

Trivers (1971) suggested how alarm calls may evolve without kin selection. He argues that even though the caller places itself in greater immediate danger, calling will evolve if hawks are less effective in, or less likely to initiate, attacks on groups with callers. If a single caller increases the fitness of the whole flock, the habit will spread when rare, even though callers have a lower fitness than their noncalling flock mates, because birds that give the call still have a higher fitness than noncallers as a whole. This is because the fitness of the few noncallers in groups with callers must be averaged with the fitness of the many that have no caller around them. Thus birds giving the call will be favored even though they are incidentally altruistic to their companions.

Trivers's argument could account for the initial spread of the gene(s) for calling, but the frequency of callers would not increase beyond a certain level under this mechanism alone. Selection will cease to favor callers when the frequency of calling is high enough for most groups to have at least one caller.

If a population of size $N$ is divided into $n$ groups with $k$ individuals in each group, and if $p$ is the proportion of callers in the total population, we can calculate how many groups will have at least one caller, assuming that individuals are assigned to groups at random. The probability that a group receives no callers is the 0th category of the hypergeometric distribution because the assignment of individuals to groups is analogous to drawing balls from an urn. If we approximate the hypergeometric distribution with the binomial, the probability of a group having no callers $[p(x=0)]$ is approximately as follows: $p(x=0) \doteq(1-p)^{k}$ (actually the $\doteq$ should be replaced by $\left.<\right)$.

If we set the flock size $k$ equal to $15, p(x=0)$ is about 0.01 when $p$ is 0.25 . Virtually no flocks are without a caller by the time the frequency of callers in the total population reaches about $25 \%$. Therefore the basic mechanism proposed by Trivers will not account for the spread of the genes for calling beyond about $25 \%$ unless the flocks under consideration are much smaller than 15 . We assume that callers are distributed at random through the population, which is not true if callers tend to associate with each other. However, there will be strong selection for noncallers to be in groups with callers, so we consider the random model as a reasonable, and perhaps conservative first approximation.

We now consider the consequence of having more than one caller in a flock. Trivers (also W. J. Smith, personal communication) suggests that if the fitness in a group is an increasing function of the number of callers present, selection will favor the further spread of the calling gene.

Let the fitness of a noncaller in a group with $x$ callers $(0<x \leq k)$ be $W n(x)$. A caller in the same group has a fitness $W n(x)-\alpha(x)$, where $\alpha(x)$ measures the cost of calling. This fitness measure includes both short- and long-term effects and assumes that the only caller-noncaller difference is the calling itself (which is reflected in $\alpha[x])$. We make the following assumptions: (1) $\alpha$ is constant, (2) $W n(x)$ is a linear function of $x(a+b x)$ (fig. 1), and (3) $p(x=0)$ is approximately zero. The average fitness of a caller $(\bar{W} c)$ is then $a+b \cdot E(x)-\alpha$, and that of a noncaller $(\bar{W} n), a+b \cdot E^{*}(x) .(E[x]$ is the average number of callers 


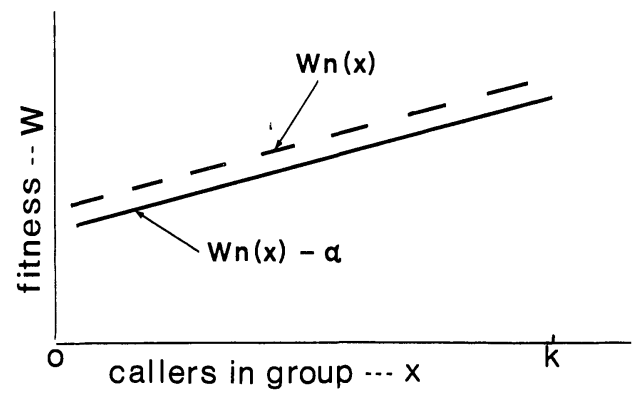

Fia. 1.-Fitness in any group increases as the number of callers in the group increases. The fitness of a noncaller is $W n(x)$; that of a caller, $W n(x)-\alpha(x)$. In this figure $\alpha$ is constant and positive (calling carries an added risk over noncalling).

surrounding a randomly chosen caller, and $E^{*}[x]$ is the average number of callers surrounding a randomly chosen noncaller.)

$$
\text { For } \quad \bar{W} c>\bar{W} n: \quad E(x)-E^{*}(x)>\frac{\alpha}{b} .
$$

As is shown in the Appendix, $E(x)-E^{*}(x) \leq 1$ in the random model, so the rule becomes approximately:

$$
\text { For } \quad \bar{W}_{c}>\bar{W} n: \quad \alpha<b .
$$

That is, the gain in fitness from adding one more caller to a flock must be greater than the penalty for calling in order for calling to spread. This suggests that the calling habit should continue to spread only if the penalty for calling is very small. If the fitness functions are nonlinear with negative second derivatives, the callers are even worse off, since it can be shown that here $E\left(x^{2}\right)>E^{*}\left(x^{2}\right)$ (i.e., the callers suffer more from this nonlinearity than do the noncallers).

We suggest two of several possible explanations of why the penalty for calling $(\alpha)$ should be small. (1) The convergent form of the call favored by selection is hard to locate (Marler 1955) and perhaps even ventriloquial (Perrins 1968). Since Trivers's initial mechanism is adequate to maintain an altruistic call at low frequency, $\alpha$ may have been reduced sufficiently (the call "perfected") to allow further spread of the habit. (2) The penalty to an individual for calling may decrease as the number of callers in a group increases, since there are more callers to share the total penalty (in this case $\alpha$ is not constant).

While the condition that $\alpha$ be made small is quite plausible, we question the basic assumption that $\alpha>0$. The only evidence that the call is (or ever was) altruistic seems to be the interpretation that this assumption is necessary to explain the extreme convergence to the difficult-to-locate form of the call. We suggest that this interpretation is incorrect. Suppose that $\alpha$ were less than or equal to zero, that there were a positive benefit associated with calling. Callers would be favored simply because they had higher fitness than noncallers. Within the class of callers, however, some would be better off than others. Altruism refers to a caller-noncaller comparison, but to explain the evolution of the form of the call we need only compare fitness within the caller class (under 
the assumption that at least some kinds of calls are better than no call at all). Obviously there has been strong selection for a difficult-to-locate call, but this does not require that the easier-to-locate calls had lower fitness than no call (Maynard Smith 1965).

We propose that the calling habit spread because of a positive benefit associated with calling $(\alpha \leq 0)$, that the caller increases its survival chances relative to its flock mates. Fitness may be an increasing function of the number of callers present (as in fig. 1), but the caller curve lies above that of the noncaller. The individual seeing the hawk would seem to be in a good position to avoid being caught by manipulating its flock mates. Having seen the hawk, the bird has two pieces of information: that there is a hawk, and the position of the hawk. If the caller passes on only part of this information to its flock mates, it will be able to use them to enhance its own safety. The noncallers are simply told that there is a hawk, and head for cover without respect to the predator's direction of approach. The caller can now protect itself by "seeking cover" (Hamilton 1971) on the far side or in the middle of the flock, or benefit from the "confusion effect" (Eibl-Eibesfeldt 1970). Undoubtedly other types of manipulation are possible, but these seem the most obvious. We use the term "manipulation" only in the sense that the caller benefits most of all from the action. Obviously the individuals called to do not act to increase the caller's safety. They use the information for their own benefit, but in doing so make it possible for the caller to benefit even more.

\section{ACKNOWLEDGMENTS}

We thank Professor J. Maynard Smith and Drs. R. L. Trivers, D. G. Chapman, W. J. Smith, and W. M. Schaffer for their helpful comments.

\section{APPENDIX}

$$
E(x)-E^{*}(x) \sim 1
$$

Define as follows: $x=$ number of callers in a group $x=0,1, \ldots, k ; g(x)=$ probability that a group has $x$ callers; $f(x)=$ probability that a caller is in a group with $x$ callers; $h(x)=$ probability that a noncaller is in a group with $x$ callers; $n=$ number of groups; $k=$ group size.

We have that

$$
\begin{aligned}
f(x) & =\text { Prob [a caller is in a group with } x \text { callers] } \\
& =\frac{\text { number of callers in groups with } x \text { callers }}{\text { number of callers in all groups }} \\
& =\frac{g(x) \cdot n \cdot x}{\sum g(x) \cdot n \cdot x}=\frac{g(x) \cdot x}{\sum g(x) \cdot x} . \\
h(x) & =\text { Prob [a noncaller is in a group with } x \text { callers] } \\
& =\frac{\text { number of noncallers in groups with } x \text { callers }}{\text { number of noncallers in all groups }} \\
& =\frac{g(x) \cdot n \cdot(k-x)}{\sum g(x) \cdot n \cdot(k-x)}=\frac{g(x) \cdot(k-x)}{\sum g(x) \cdot(k-x)} .
\end{aligned}
$$


We will use the following expectations:

$$
\begin{gathered}
\sum g(x) \cdot x=U_{x} ; \quad \sum g(x) \cdot x^{2}=U_{2 x} ; \\
V_{x}=\sum g(x)\left(x-U_{x}\right)^{2}=U_{2 x}-U_{x}^{2} ; \\
E(x)=\text { average } x \text { for a caller }=\sum x \cdot f(x) ; \\
E^{*}(x)=\text { average } x \text { for a noncaller }=\sum x \cdot h(x) .
\end{gathered}
$$

Theorem: $E(x) \geq E^{*}(x)$ by an amount that depends on $U_{x}$ and $V_{x}$.

$$
\begin{aligned}
E(x) & =\sum x \cdot f(x)=\frac{\sum g(x) \cdot x^{2}}{\sum g(x) \cdot x}=\frac{U_{2 x}}{U_{x}}=\frac{V_{x}+U_{x}^{2}}{U_{x}} . \\
E(x) & =U_{x}+\frac{V_{x}}{U_{x}} \\
E^{*}(x) & =\sum x \cdot h(x)=\frac{\sum g(x) \cdot(k-x) x}{\sum g(x) \cdot(k-x)} \\
& =\frac{U_{x} k-U_{2 x}}{k-U_{x}}=\frac{U_{x} k-V_{x}-U_{x}^{2}}{k-U_{x}} \\
& =\frac{U_{x}\left(k-U_{x}\right)}{k-U_{x}}-\frac{V_{x}}{k-U_{x}} . \\
E^{*}(x) & =U_{x}-\frac{V_{x}}{k-U_{x}} .
\end{aligned}
$$

So

$$
E(x)-E^{*}(x)=\frac{V_{x}}{U_{x}}+\frac{V_{x}}{k-U_{x}}=\frac{V_{x} \cdot k}{U_{x}\left(k-U_{x}\right)} .
$$

In the balls and urn model

$$
\begin{aligned}
& U_{x}=P \cdot k \\
& V_{x}=P \cdot k(1-P)\left(\frac{N-k}{N-1}\right) \sim P \cdot k(1-P) \quad \text { if } k \text { is small relative to } N .
\end{aligned}
$$

Thus

$$
E(x)-E^{*}(x) \sim \frac{P \cdot k \cdot k(1-P)}{P \cdot k \cdot k(1-P)}=1
$$

\section{LITERATURE CITED}

Eibl-Eibesfeldt, I. 1970. Ethology, the biology of behavior. Holt, Rhinehart \& Winston, New York. 530 pp.

Emlen, J. M. 1973. Ecology: an evolutionary approach. Addison-Wesley, Reading, Mass. $493 \mathrm{pp}$.

Hamilton, W. D. 1964. The genetical evolution of social behavior. J. Theoret. Biol. 27:1-52. 1971. Geometry for the selfish herd. J. Theoret. Biol. 31:295-311.

Marler, P. 1955. Characteristics of some animal calls. Nature 176:6-8.

Maynard Smith, J. 1965. The evolution of alarm calls. Amer. Natur. 94:59-63.

Perrins, C. M. 1968. The purpose of the high-intensity alarm call in small passerines. Ibis 110:200-201.

Thorpe, W. H. 1961. Bird song: the biology of vocal communication and expressions in birds. Cambridge University Press, Cambridge. 142 pp. 
Trivers, R. L. 1971. The evolution of reciprocal altruism. Quart. Rev. Biol. 46:35-57.

Williams, G. C., ed. 1970. Group selection. Aldine-Atherton, Chicago. 210 pp.

\section{Erio L. Charnov} JOHN R. KREBS

Department of Biology

UNIVERSITY OF UTAH

Salt Lake City, Utah 84112

Department of Zoology

U.C.N.W.

BANGOR, WALES

July 9, 1974 